\title{
Clinical Spectrum, Risk Factors, and Behavioral Abnormalities among Dementia Subtypes in a North Indian Population: A Hospital-Based Study
}

\author{
Suman Kushwaha ${ }^{a}$ Puneet Talwar ${ }^{b}$ Aldrin Anthony ${ }^{a}$ Meena Gupta ${ }^{c}$ \\ Kiran Bala ${ }^{a}$ Rachna Agarwal ${ }^{a}$ Vibha Sharma $^{a}$ Ritushree Kukreti $^{b}$ \\ ${ }^{a}$ Institute of Human Behaviour and Allied Sciences (IHBAS), Delhi, India; ${ }^{b}$ Genomics and \\ Molecular Medicine Unit, Institute of Genomics and Integrative Biology (IGIB), Council of \\ Scientific and Industrial Research (CSIR), Delhi, India; 'Paras Hospitals, Gurgaon, India
}

\section{Keywords}

Aging - Cognition - Risk factors - Dementia - Behavioral and psychological symptoms of dementia

\begin{abstract}
Background: As variability in the clinical profile of dementia subtypes had been reported with regional differences across the world, we conducted a retrospective hospital-based study in a North Indian population. Methods: We retrieved patient records from 2007 to 2014 for details of clinical evaluation, diagnosis, neuroimaging, biochemical investigations, and follow-up of 1,876 patients with dementia (PwD), and the data were analyzed using descriptive statistics. Results: Of the total PwD, Alzheimer disease (AD) accounted for $30 \%$ followed by vascular dementia (VaD) 26\%, mixed dementia (MD) 21\%, Parkinson-related dementia 11\%, frontotemporal dementia (FTD) 7\%, and infective dementia 5\%. Of all PwD excluding the infective group ( $n=1,777), 63 \%$ were men, 39\% were from rural areas, $87 \%$ had behavioral abnormalities along with cognitive deficits, and $73 \%$ had impaired ADLs. Among dementia subtypes, a positive family history, cardiovascular and metabolic risk factors, and behavioral abnormalities were found to be distributed. However, there existed a predominance of specific behavioral pattern in each subtype. The mean duration of follow-up varied from $2.9 \pm 2.3(\mathrm{VaD})$ to $3.6 \pm$ 2.1 (AD) and greater than $30 \%$ were found to be stable on treatment (except in dementia with Lewy body). Conclusions: This large hospital-based study provides a distribution pattern and clinical spectrum of dementia subtypes in a North Indian population.
\end{abstract}




\section{Introduction}

Dementia can be defined as a clinical syndrome characterized by impaired memory and activities of daily living (ADL), altered behavior, personality, and other cognitive dysfunctions [1]. Since the last decade, it has become a global burden with a rapid increase in its prevalence worldwide [2, 3]. However, the data on dementia subtypes are highly variable among countries with more variation being observed in developing countries as compared to developed countries due to factors such as cultural and socioeconomic variability and a lack of methodological uniformity [4]. An increasing dementia burden will impose a huge socioeconomic burden in countries worldwide with a far more complicating situation in countries such as India and China [5-8]. The annual economic burden for dementia care in developing countries is estimated to be around USD 73 billion which excludes societal care as it is either unavailable or inaccessible [6]. It has now been universally accepted that cognitive impairment, even in the initial stages, is a major cause of disability and caregiver burden $[9,10]$. The majority of studies describing dementia subtypes have mainly been community-based studies from developed countries as compared to the limited number of studies from developing countries except China probably due to a lack of expertise in the field of cognitive neurology.

Ageing is a universal phenomenon, and dementia is strongly associated with increasing age. Although age is the most consistent nonmodifiable risk factor for dementia, family history and genetic predisposition play an important role. Previous studies have demonstrated an association with several modifiable risk factors including lower literacy rate, nutritional status, and metabolic and cardiovascular factors with higher burden of dementia mainly in developing countries $[6,11]$. Dementia can be classified into two major categories, primary or degenerative and secondary or acquired. The most common degenerative dementias are Alzheimer disease (AD), frontotemporal dementia (FTD), Parkinson disease dementia (PDD), and dementia with Lewy bodies (DLB) [12]. Secondary causes mainly include vascular, CNS infections, trauma, metabolic derangements, and other reversible/treatable causes [13-15]. Although cognitive dysfunction predominates the symptomatology, behavioral and psychological symptoms of dementia (BPSD) are an integral part of dementia which is under-recognized. The understanding of BPSD would be helpful for an early diagnosis and better management so as to improve the patients' quality of life $[16,17]$.

The diagnosis and management of dementia subtypes require expertise along with adequate infrastructure. The specialized clinics are instrumental in categorizing the dementia into subtypes, which helps to understand the comparative symptomatology and management. Subtyping dementia is still a challenging job in developing countries such as India because a limited number of centers have dedicated clinics and experts for cognitive disorders. Here, we aimed to present the clinical spectrum of dementia subtypes in a large retrospective cohort study involving 1,876 systematically evaluated and managed patients with dementia (PwD) at a tertiary care hospital in Delhi, India. We report the demographic and clinical profile of dementia subtypes along with associated risk factors and specific behavioral abnormalities.

\section{Materials and Methods}

\section{Medical Record Review}

We conducted a retrospective cohort study to evaluate the clinical subtypes of dementia in the Neurobehavioral and Neurology Outpatient Clinic at the Institute of Human Behavior and Allied Sciences (IHBAS), a tertiary care neuropsychiatry institute in Delhi, North India. Being a referral and specialized neurology service provider, the institute caters to a large 


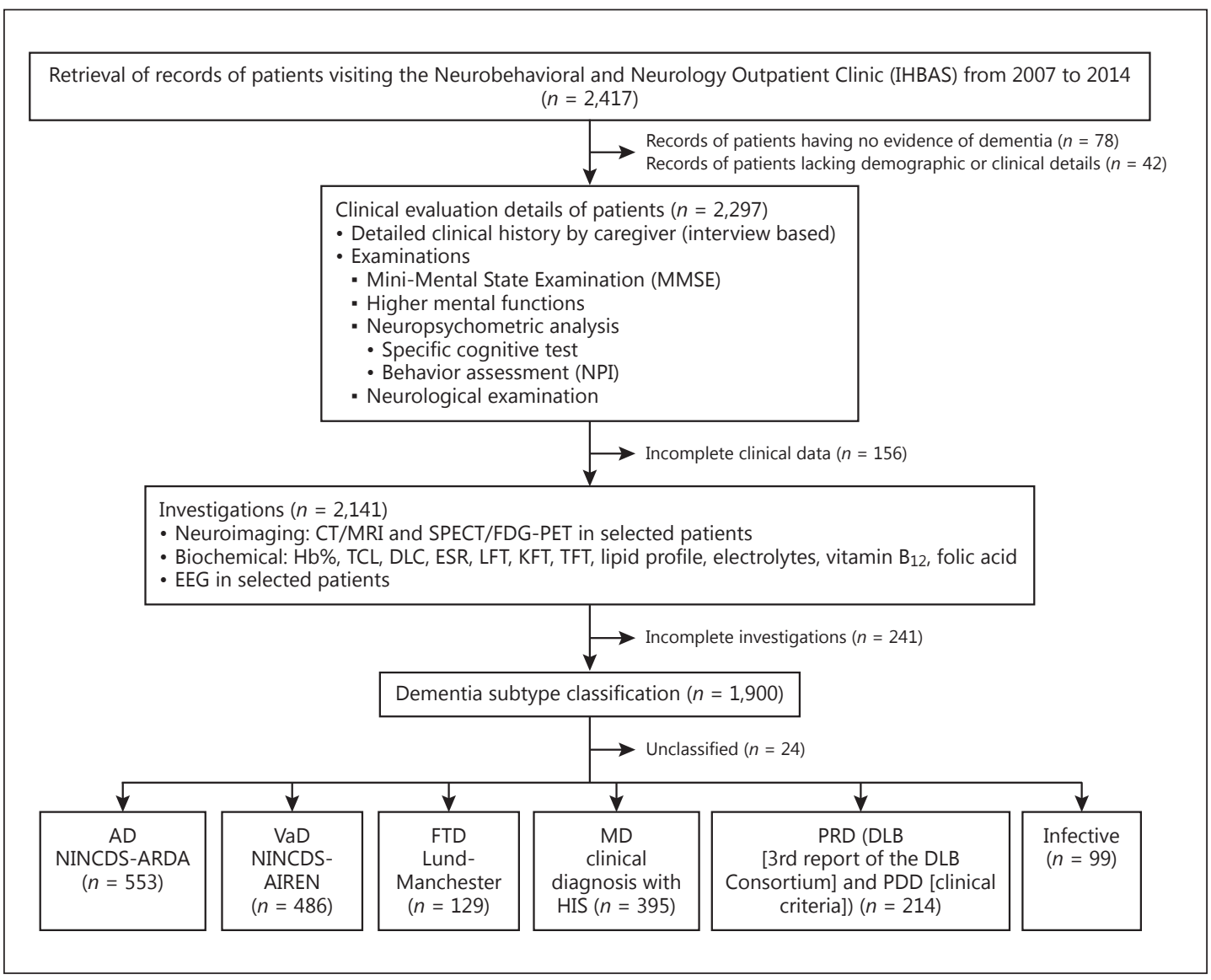

Fig. 1. Schematic standardized protocol for the uniform assessment of patients. NPI, Neuropsychiatry Inventory; AD, Alzheimer disease; VaD, vascular dementia; FTD, frontotemporal dementia; MD, mixed dementia; PRD, Parkinson-related dementia; DLB, dementia with Lewy bodies; PDD, Parkinson disease dementia.

patient pool from different parts of North India and cases referred by general practitioners. The demographic details, clinical evaluation, diagnosis, management, and follow-up data related to consecutive PwD were accessed and retrieved from the records of the previous 8 years from 2007 to 2014. The present study received local institutional approval with exemption from the requirement of obtaining written informed consent. The data were retrieved by screening the files of the PwD year wise (S.K. and A.A.) and they were simultaneously entered into the database (Excel sheet) for further analysis. We followed a pre-established protocol that is used for the uniform assessment of patients at the Neurobehavioral Clinic (NBC) (Fig. 1).

\section{Clinical Assessment}

Neurologists with experience and an interest in cognitive disorders performed the evaluation of PwD (M.G., S.K., A.A., and K.B.). This included history taking by the caregivers regarding the symptomatology and chronology of the cognitive decline, behavioral problems, and impairment of ADL. The history of chronic medical illness, head trauma, drug intake, toxin exposure, and metabolic and endocrine disorders along with the detailed family history was obtained. All the patients underwent neurological examination that included Mini-Mental State Examination (MMSE), detailed higher mental function examination for assessing lobar 
function, Neuropsychiatry Inventory (NPI) for behavior assessment [18], and the motor system examination. The 30-item MMSE was used, which is a questionnaire-based tool that evaluates the five areas of cognitive function (orientation, registration, attention and calculation, recall, and language) [19]. In our study, the severity of cognitive dysfunction in patients is assessed by the MMSE scores which were categorized as mild (MMSE $=19-24$ ), moderate (MMSE $=10-20)$, and severe (MMSE $=0-10)$. We have used a Hindi adaptation of MMSE referred to as a Hindi Mental State Examination (HMSE) for the illiterates with minor modifications such as subtraction instead of word spell [20]. In a follow-up, the patient is considered "stable" if he or she remains in the same severity group and "deteriorated" if there is a change from the mild to the moderate or the moderate to the severe group based on MMSE scoring.

Neuropsychological assessment and psychiatry consultation were taken in selected patients. Detailed higher mental function assessing the cognitive functions of each lobe was performed. The standardized neuropsychological batteries including NIMHANS neuropsychiatry battery [21] and PGI Battery of Brain Dysfunction [22] were used for detailed cognitive dysfunctions. The original NPI was translated into Hindi by two neurologists (S.K. and A.A.) and a clinical psychologist (V.S.). The NPI consisted of 12 neuropsychiatric symptoms in the form of a questionnaire administered to the caregiver by the trained psychologist for assessing behavioral abnormalities.

The patients were investigated for secondary causes of dementia. Routine hematological and biochemical parameters were evaluated. Thyroid function, serum homocysteine, vitamin $B_{12}$, and folic acid estimation were assessed in patients suspected of endocrine and metabolic disorders. Cerebrospinal fluid examination was done in selected patients to rule out chronic CNS infections. Neuroimaging using computerized tomography (head) or magnetic resonance imaging (brain) was done in all patients. Fluorodeoxyglucose-positron emission tomography or single-photon emission computed tomography was done in selected patients. The final diagnosis of dementia subtypes was made after evaluating the above findings.

\section{Subtype Classification}

The diagnosis of dementia subtypes was arrived at by consensus upon reviewing clinical, neuropsychological, brain imaging data and biochemical investigations (M.G., S.K., K.B., A.A.). Dementia was diagnosed according to the DSM-IV criteria [23].

Dementia subtypes were classified using international consensus clinical criteria. AD was diagnosed in patients who fulfilled the National Institute of Neurological and Communicative Disorders and Stroke and the Alzheimer's Disease and Related Disorders Association (NINCDSARDA) criteria for probable or possible AD [24]. Vascular dementia (VaD) was diagnosed in patients who fulfilled National Institute of Neurological Disorders and Stroke and Association Internationale pour la Recherché et l'Enseignement en Neurosciences (NINDS-AIREN) criteria for probable or possible VaD [25, 26]. Mixed dementia (MD) involves AD with cerebrovascular disease, and there is a lack of established criteria for MD. We used the operational definition that includes the clinical history and the HIS score of 5 or 6 for diagnosing MD [27]. A Lund-Manchester criterion was used to diagnose FTD $[28,29]$, and the 3rd report of the DLB Consortium was used for DLB diagnosis [30]. As PDD is clinically a dysexecutive-visuospatial syndrome which cannot be diagnosed with the DSM-IV and as the criteria for the diagnosis of PDD is still under development, the patients were diagnosed clinically. The Parkinson diseaseCognitive Rating Scale (PDCRS) was used to measure the cognitive deficits associated with Parkinson disease [31]. Information regarding alcoholism and smoking was provided by the caregiver, and chronic alcoholics and substance abuse cases were excluded from the study.

Parkinson-related dementia (PRD) includes PDD and DLB. All the patients were followed up at regular intervals. 
Table 1. Demographic and clinical characteristics of patients with different dementia subtypes

\begin{tabular}{|c|c|c|c|c|c|c|}
\hline \multicolumn{7}{|l|}{ Demographic characteristics } \\
\hline Age, years & $70.0(48-100)$ & $65.0(40-90)$ & $70.0(60-91)$ & $58.0(40-78)$ & $62.0(60-77)$ & $<0.0001$ \\
\hline Age at onset, years & $66.0(47-99)$ & $63.5(36-86)$ & $69(56-86)$ & $54.5(36-77)$ & $61.0(56-73)$ & $<0.0001$ \\
\hline $\begin{array}{l}\text { Male } \\
\text { Female }\end{array}$ & $\begin{array}{l}326(59.0) \\
227(41.0)\end{array}$ & $\begin{array}{l}345(71.0) \\
141(29.0)\end{array}$ & $\begin{array}{l}249(63.0) \\
146(37.0)\end{array}$ & $\begin{array}{l}73(56.4) \\
56(43.6)\end{array}$ & $\begin{array}{r}122(57.0) \\
92(43.0)\end{array}$ & \\
\hline Educational status & & & & & & - \\
\hline $\begin{array}{l}\text { Illiterate } \\
\text { High school } \\
\text { Above high school }\end{array}$ & $\begin{array}{c}437(79.1) \\
84(15.2) \\
32(5.7)\end{array}$ & $\begin{array}{c}334(68.8) \\
105(21.7) \\
46(9.5)\end{array}$ & $\begin{array}{l}326(82.6) \\
34(8.6) \\
35(8.8)\end{array}$ & $\begin{array}{l}99(76.9) \\
13(10.3) \\
17(12 . .8)\end{array}$ & $\begin{array}{r}153(71.4) \\
31(14.3) \\
31(14.3)\end{array}$ & \\
\hline \multicolumn{7}{|l|}{ Clinical characteristics } \\
\hline $\begin{array}{l}\text { MMSE score } \\
\text { Memory impairment }\end{array}$ & $12.7 \pm 6.1$ & $14.9 \pm 5.3$ & $13.8 \pm 5.4$ & $11.5 \pm 6.2$ & $14.7 \pm 9.9$ & $\begin{aligned} & 0.009 \\
< & 0.0001^{b}\end{aligned}$ \\
\hline $\begin{array}{l}\text { Mild } \\
\text { Moderate } \\
\text { Severe }\end{array}$ & $\begin{array}{r}58(10.5) \\
232(42.0) \\
263(47.5)\end{array}$ & $\begin{array}{l}151(31.1) \\
183(37.7) \\
152(31.3)\end{array}$ & $\begin{array}{r}69(17.5) \\
198(50.1) \\
128(32.4)\end{array}$ & $\begin{array}{l}27(20.9) \\
43(33.3) \\
59(45.8)\end{array}$ & $\begin{array}{r}52(24.3) \\
53(24.8) \\
109(51.0)\end{array}$ & \\
\hline ADL & & & & & & $<0.0001^{\mathrm{b}}$ \\
\hline $\begin{array}{l}\text { Unimpaired } \\
\text { Impaired }\end{array}$ & $\begin{array}{l}295(53.3) \\
258(46.7)\end{array}$ & $\begin{array}{r}408(83.9) \\
78(16.1)\end{array}$ & $\begin{array}{l}206(52.2) \\
189(47.8)\end{array}$ & $\begin{array}{l}93(71.8) \\
36(28.2)\end{array}$ & $\begin{array}{r}183(85.7) \\
31(14.3)\end{array}$ & \\
\hline Behavioral abnormalities & & & & & & $0.111^{\mathrm{b}}$ \\
\hline
\end{tabular}

Values represent median (range), mean $\pm \mathrm{SD}$, or $n(\%)$. AD, Alzheimer disease; VaD, vascular dementia; MD, mixed dementia; FTD, frontotemporal dementia; DLB, dementia with Lewy bodies; PDD, Parkinson disease dementia. ${ }^{\text {a }}$ One-way ANOVA. ${ }^{\mathrm{b}} \chi^{2}$ test.

\section{Statistical Methods}

Continuous data were expressed as mean \pm SD and categorical data as frequency. $p$ value was calculated using the $t$ test or the one-way analysis of variance (ANOVA) for continuous data and by the $\chi^{2}$ or Fisher exact test for variables expressed as percentages. Statistical analysis was performed using Statistical Package for Social Sciences (SPSS, version 19.0, SPSS Corporation, Chicago, IL, USA) along with online analysis tools from http://vassarstats.net/ newcs.html.

\section{Results}

\section{Demographic Characteristics}

The median age and median age at onset of patients with FTD was 58.0 (40-78) and 54.5 (36-77) years, respectively, which was significantly lower than in the other dementia subtypes. The mean duration of illness was highest in the FTD group ( $5.0 \pm 1.4$ years) and lowest in the PRD group ( $3.9 \pm 1.8$ years). The median age and median age at onset were found to be lower for $\mathrm{VaD}$ as compared to $\mathrm{AD}$ and MD groups. The infective subgroup was not included due to the presence of a high level of heterogeneity and complexity among its subpathologies, which cannot be combined together. The demographic characteristics of PwD excluding the infective dementia group $(n=1,777)$ are presented in Table 1 . Of the 1,777 patients, 1,115 were men (63\%), 1,350 were illiterate (76\%), and 692 were from rural areas (39\%). 


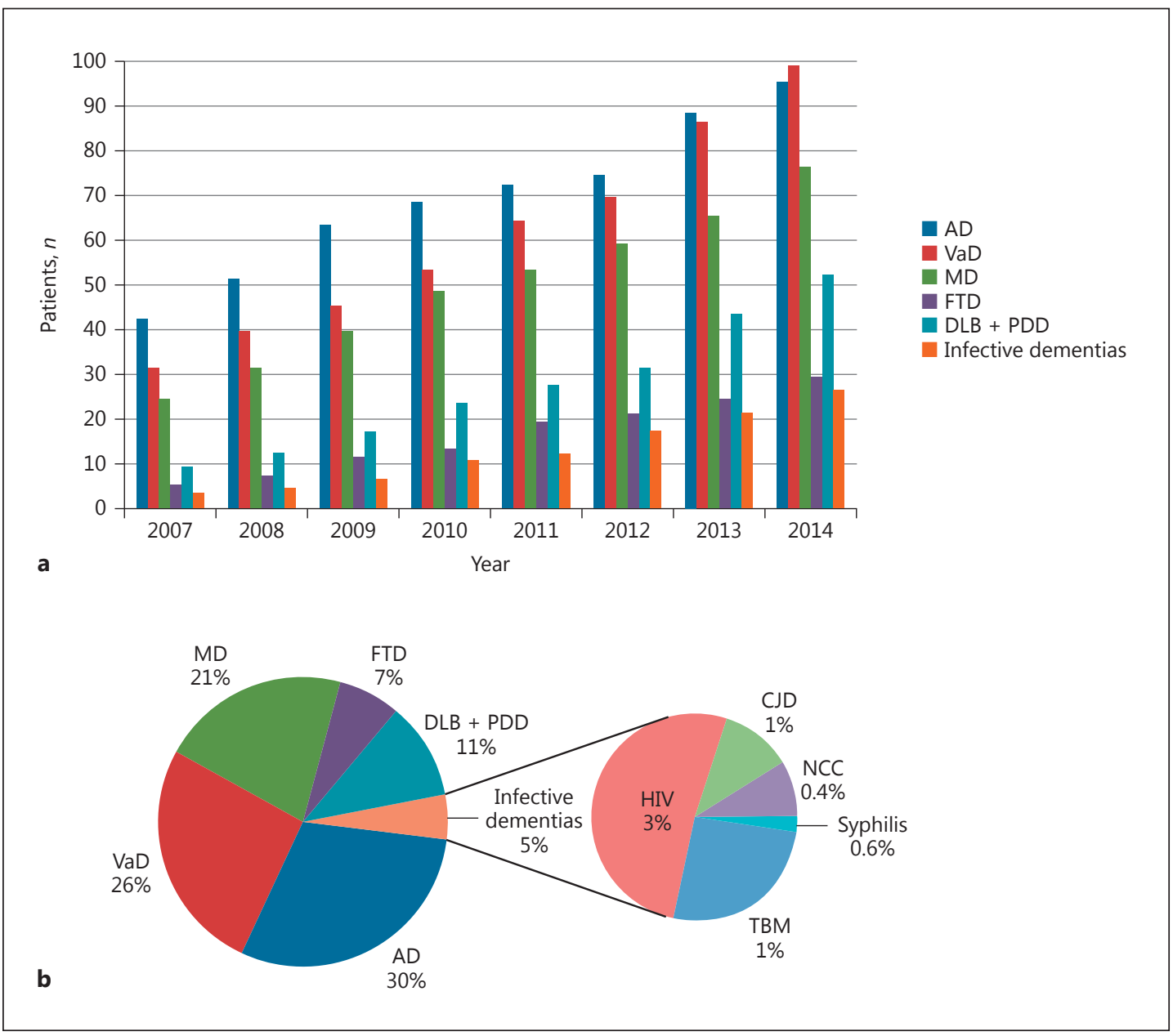

Fig. 2. a Distribution per year of dementia subtypes from 2007 to 2014. AD, Alzheimer disease; VaD, vascular dementia; MD, mixed dementia; FTD, frontotemporal dementia; DLB, dementia with Lewy bodies; PDD, Parkinson disease dementia. b Distribution of patients with dementia (PwD) subtypes. TBM, tuberculous meningitis; HIV, human immunodeficiency virus infection (HIV/AIDS); NCC, neurocysticercosis; CJD, CreutzfeldtJakob disease.

\section{Distribution of Dementia Subtypes}

In our retrospective study, we retrieved and evaluated the data of 1,876 different PwD subtypes. The total number of PwD increased steadily over the 8-year period from 114 in 2007 to 377 in 2014. The increase in dementia patients varied annually from 10 to $26 \%$ between 2007 and 2014 years. The numbers of patients with AD were found to be marginally higher than those of patients with other dementia subtypes from 2007 to 2013 except in 2014 when the number of VaD subjects was marginally higher than that of AD subjects. Among all dementia subtypes, the number of infective dementia was found to be the lowest every year. The distribution of different PwD subtypes is presented in Figure 2a.

\section{Frequency Distribution of Dementia Subtypes}

Among 1,876 PwD, AD was found to be the most common form of dementia with 553 cases (30\%) followed by $486 \mathrm{VaD}$ cases (26\%). MD, PRD, and FTD were found in 395 (21\%), $214(11 \%)$, and 129 (7\%) subjects, respectively. The infective dementia was diagnosed in 99 
Table 2. Distribution of behavioral complaints in different dementia subtypes

\begin{tabular}{|c|c|c|c|c|c|c|c|c|}
\hline \multirow{2}{*}{$\begin{array}{l}\text { Behavioral } \\
\text { complaints }\end{array}$} & \multicolumn{5}{|c|}{ Dementia subtypes, $n(\%)$} & \multirow[t]{2}{*}{$\chi^{2}$} & \multirow[t]{2}{*}{$\mathrm{df}$} & \multirow[t]{2}{*}{$p$} \\
\hline & $\begin{array}{l}A D \\
(n=553)\end{array}$ & $\begin{array}{l}\mathrm{VaD} \\
(\mathrm{n}=486)\end{array}$ & $\begin{array}{l}\text { MD } \\
(n=395\end{array}$ & $\begin{array}{l}\text { FTD } \\
(n=129)\end{array}$ & $\begin{array}{l}\text { PRD } \\
(n=214)\end{array}$ & & & \\
\hline Depression & $77(14.0)$ & $133(27.4)$ & $153(38.7)$ & 23 (17.9) & $31(14.3)$ & 95.31 & 4 & $<0.0001$ \\
\hline Aggression & $223(40.3)$ & $229(47.2)$ & $146(37)$ & $40(30.8)$ & $31(14.3)$ & 71.67 & 4 & $<0.0001$ \\
\hline Hallucination & $80(14.4)$ & $36(7.5)$ & $69(17.4)$ & $20(15.4)$ & $183(85.7)$ & 592.76 & 4 & $<0.0001$ \\
\hline Suspicion & $220(39.8)$ & $23(4.7)$ & $26(6.5)$ & $3(2.6)$ & $19(8.9)$ & 324.41 & 4 & $<0.0001$ \\
\hline Perseveration & $74(13.3)$ & $32(6.6)$ & $28(7.2)$ & $23(17.9)$ & $4(2.1)$ & 43.48 & 4 & $<0.0001$ \\
\hline Self-muttering & $52(9.4)$ & $18(3.8)$ & $43(10.9)$ & $10(7.7)$ & $0(0.0)$ & 38.78 & 4 & $<0.0001$ \\
\hline Disinhibition & 199 (35.9) & $55(11.3)$ & $86(21.7)$ & $66(51.3)$ & $31(14.3)$ & 147.49 & 4 & $<0.0001$ \\
\hline Abusive & $159(28.7)$ & $18(3.8)$ & $26(6.5)$ & $3(2.6)$ & $0(0.0)$ & 236.94 & 4 & $<0.0001$ \\
\hline Irritable & $251(45.3)$ & 87 (17.9) & $60(15.2)$ & $13(10.3)$ & $12(5.5)$ & 220.01 & 4 & $<0.0001$ \\
\hline Withdrawn & $82(14.9)$ & $41(8.5)$ & 77 (19.6) & $17(12.8)$ & $7(3.2)$ & 44.12 & 4 & $<0.0001$ \\
\hline Delusions & 70 (12.7) & $0(0.0)$ & $0(0.0)$ & $3(2.6)$ & $3(1.2)$ & 139.77 & 4 & $<0.0001$ \\
\hline Wandering & 226 (40.9) & $23(4.7)$ & $9(2.2)$ & $10(7.7)$ & $0(0.0)$ & 421.73 & 4 & $<0.0001$ \\
\hline Apathy & 57 (10.3) & $46(9.4)$ & $51(13.0)$ & $33(25.6)$ & $0(0.0)$ & 59.23 & 4 & $<0.0001$ \\
\hline Incontinence & 208 (37.6) & $232(47.8)$ & 204 (51.6) & 74 (57.7) & $93(43.4)$ & 28.52 & 4 & $<0.0001$ \\
\hline
\end{tabular}

$\mathrm{AD}$, Alzheimer disease; VaD, vascular disease; MD, mixed disease; FTD, frontotemporal dementia; PRD, Parkinson-related disease.

individuals, which accounts for $5 \%$ of the total dementia cases and includes subjects with different etiologies: 52 (3\%) had human immunodeficiency virus infection (HIV/AIDS), 25 (1\%) had tuberculous meningitis, $11(1 \%)$ had Creutzfeldt-Jakob disease, $8(0.4 \%)$ had neurocysticercosis, and $3(0.6 \%)$ had syphilis. The frequency distribution of different dementia subtypes is depicted in Figure $2 \mathrm{~b}$.

\section{Clinical Characteristics}

A significant difference was observed in the disease severity status of patients based on MMSE assessment among different dementia subtypes $(p=0.009)$. The moderate and severe cases were higher $(40 \%)$ as compared to mild dementia with $20 \%$ cases $(n=357)$. Of the 1,777 patients, $592(33 \%)$ had impaired ADL at the time of presentation but on subsequent evaluation $73 \%$ of the total patients had impaired ADL and 1,544 (87\%) had behavioral abnormalities. Specifically, ADL was found to be more impaired in patients with AD and MD. All patients of DLB were found to have behavioral abnormalities mainly hallucinations, which is one of the most common clinical feature reported in this subtype [32].

In our study, we have also focused on the various BPSD presented in different PwD subtypes (Table 2). In the 1,777 patients, incontinence was observed to be the most common problem reported by 811 (46\%) patients followed by aggression in $669(38 \%)$ and disinhibition in $436(25 \%)$ patients. We observed that suspiciousness (39.8\%), abusiveness $(28.7 \%)$, and irritability $(45.3 \%)$ along with delusions $(12.7 \%)$ and a tendency to wander $(40.9 \%)$ were found most commonly in AD. Depression, self-muttering, and social withdrawal was most commonly observed in MD with 153 (38.7\%), 43 (10.9\%), and 77 (19.6\%) patients, respectively. Aggression and hallucination were reported mostly by patients with VaD (47.2\%) and PRD (85.7\%), respectively. Perseveration (17.9\%), disinhibition (51.3\%), and apathy $(25.6 \%)$ were predominantly diagnosed in FTD cases. Among AD patients, irritable behavior was the most predominant symptom (45.3\%) whereas incontinence was the most common presenting symptom in patients with $\mathrm{VaD}$ (47.8\%), MD (51.6\%), and FTD (57.7\%). 
Table 3. Association of behavioral complaints among different dementia subtypes

\begin{tabular}{|c|c|c|c|c|c|c|c|c|c|c|c|c|c|c|c|}
\hline \multirow{3}{*}{$\begin{array}{l}\text { Behavioral } \\
\text { complaints }\end{array}$} & \multicolumn{15}{|c|}{ Dementia subtypes } \\
\hline & \multicolumn{3}{|c|}{ AD vs. others } & \multicolumn{3}{|c|}{ VaD vs. others } & \multicolumn{3}{|c|}{ MD vs. others } & \multicolumn{3}{|c|}{ FTD vs. others } & \multicolumn{3}{|c|}{ PRD vs. others } \\
\hline & $\chi^{2}$ & df & $p$ & $\chi^{2}$ & df & $p$ & $\chi^{2}$ & df & $p$ & $\chi^{2}$ & df & $p$ & $\chi^{2}$ & df & $p$ \\
\hline Depression & 40.71 & 1 & $<0.0001$ & 5.66 & 1 & 0.0174 & 65.92 & 1 & $<0.0001$ & 2.46 & 1 & 0.1168 & 11.04 & 1 & 0.0009 \\
\hline Aggression & 2.45 & 1 & 0.1175 & 25.89 & 1 & $<0.0001$ & 0.10 & 1 & 0.7518 & 2.61 & 1 & 0.1062 & 55.60 & 1 & $<0.0001$ \\
\hline Hallucination & 25.54 & 1 & $<0.0001$ & 81.58 & 1 & $<0.0001$ & 5.67 & 1 & 0.0173 & 3.27 & 1 & 0.0706 & 578.07 & 1 & $<0.0001$ \\
\hline Suspicion & 321.21 & 1 & $<0.0001$ & 66.22 & 1 & $<0.0001$ & 35.57 & 1 & $<0.0001$ & 20.05 & 1 & $<0.0001$ & 9.99 & 1 & 0.0016 \\
\hline Perseveration & 17.63 & 1 & $<0.0001$ & 5.18 & 1 & 0.0228 & 2.40 & 1 & 0.1213 & 12.74 & 1 & 0.0004 & 15.27 & 1 & $<0.0001$ \\
\hline Self-muttering & 7.67 & 1 & 0.0056 & 10.75 & 1 & $<0.0001$ & 12.39 & 1 & 0.0004 & 0.13 & 1 & 0.7184 & 18.09 & 1 & $<0.0001$ \\
\hline Disinhibition & 56.84 & 1 & $<0.0001$ & 63.13 & 1 & $<0.0001$ & 2.09 & 1 & 0.1483 & 53.26 & 1 & $<0.0001$ & 13.27 & 1 & 0.0003 \\
\hline Abusive & 230.66 & 1 & $<0.0001$ & 40.62 & 1 & $<0.0001$ & 12.67 & 1 & 0.0004 & 11.66 & 1 & 0.0006 & 31.90 & 1 & $<0.0001$ \\
\hline Irritable & 206.22 & 1 & $<0.0001$ & 12.85 & 1 & 0.0003 & 20.78 & 1 & $<0.0001$ & 14.36 & 1 & 0.0002 & 44.42 & 1 & $<0.0001$ \\
\hline Withdrawn & 3.60 & 1 & 0.0578 & 10.56 & 1 & 0.0012 & 21.87 & 1 & $<0.0001$ & 0.03 & 1 & 0.8625 & 19.40 & 1 & $<0.0001$ \\
\hline Delusions & 137.76 & 1 & $<0.0001$ & 29.89 & 1 & $<0.0001$ & 22.69 & 1 & $<0.0001$ & 1.29 & 1 & 0.256 & 5.04 & 1 & 0.0248 \\
\hline Wandering & 419.95 & 1 & $<0.0001$ & 55.94 & 1 & $<0.0001$ & 65.01 & 1 & $<0.0001$ & 5.83 & 1 & 0.0158 & 43.21 & 1 & $<0.0001$ \\
\hline Apathy & 0.04 & 1 & 0.8415 & 0.80 & 1 & 0.3711 & 3.08 & 1 & 0.0793 & 33.50 & 1 & $<0.0001$ & 28.61 & 1 & $<0.0001$ \\
\hline Incontinence & 20.84 & 1 & $<0.0001$ & 1.19 & 1 & 0.2753 & 7.25 & 1 & 0.0071 & 7.71 & 1 & 0.0055 & 0.47 & 1 & 0.493 \\
\hline
\end{tabular}

AD, Alzheimer disease; VaD, vascular disease; MD, mixed disease; FTD, frontotemporal dementia; PRD, Parkinson-related disease.

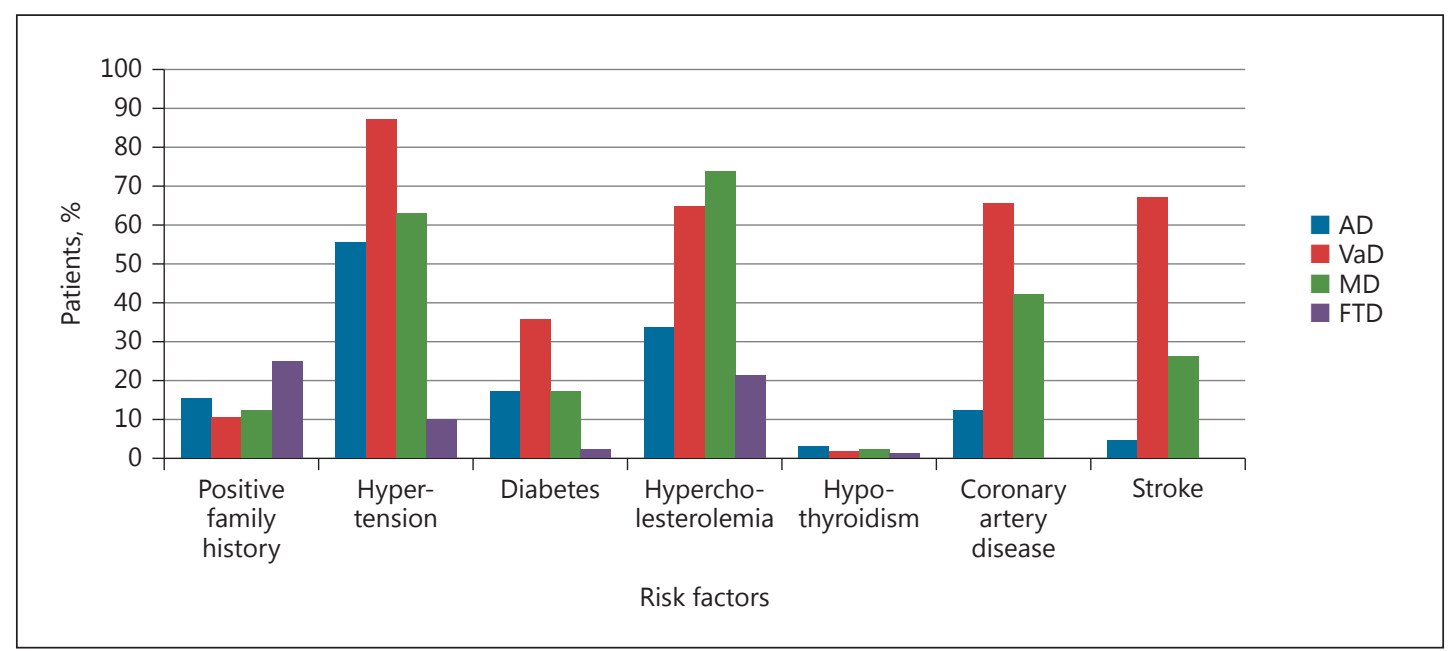

Fig. 3. Distribution of risk factors among patients with different dementia (PwD) subtypes. AD, Alzheimer disease; VaD, vascular dementia; MD, mixed dementia; FTD, frontotemporal dementia.

The association of different behavioral complaints with dementia subtypes was assessed (Table 3), and a statistically significant association of multiple behavioral issues was observed among different dementias.

The major risk factors of dementia subtypes are presented in Figure 3. Positive family history varies from $8.9 \%$ in PRD to $25 \%$ in FTD. Vascular risk factors, mainly hypertension and type 2 diabetes, were found to be most commonly present in VaD cases followed by MD and AD. Hypertension was found to be the most prevalent in 426 patients with $\mathrm{VaD}(87.7 \%)$, 249 with MD (63\%), and 309 with AD (55.8\%). Type 2 diabetes was reported in 174 patients with VaD (35.8\%), 69 patients with MD (17.4\%), and 95 patients with AD (17.1\%). Further, hypercholesterolemia was found to be present in 293 patients with MD (74.3\%), which is higher as compared to 317 and 187 with $\operatorname{VaD}(65.2 \%)$ and $\mathrm{AD}$ (33.8\%), respectively. A higher 
proportion of patients with alcoholism were present only in the VaD group (5.7\%) whereas smoking was more commonly seen in patients with $\mathrm{AD}(8.8 \%)$, VaD (5.7\%), and FTD (7.7\%). Vitamin $B_{12}$ deficiency was found in $26 \%$ and hypothyroidism was present in $2.6 \%$ of the PwD. The mean duration of follow-up varies from $2.92 \pm 2.3$ for VaD to $3.62 \pm 2.1$ for AD. More than $30 \%$ of the patients were stable on symptomatic treatment across all dementia subtypes except in the DLB group.

\section{Discussion}

In developing countries, there is uncertainty regarding the frequency of dementia subtypes with fewer studies and widely varying estimates. The reports on dementia subtypes available in the literature are from community as well as hospital-based studies $[33,34]$. On comparing the frequency with other Asian countries, Korean community-based study have shown a lower frequency of $0.34-1.5 \%$ of PwD as compared to $4.7-6.7 \%$ in Japan, $1.8-6.1 \%$ in China, and $2.4 \%$ in India [35, 36]. In the present hospital-based study, the clinical spectrum, risk factor, and behavioral changes were evaluated systematically in 1,876 PwD from 2007 to 2014. To date, this is the largest hospital-based study describing dementia subtypes from Asia, which provided a comprehensive account of risk factors and a detailed behavioral pattern in comparison with other studies reporting mainly clinical profiles of dementia subtypes (Tables 4, 5).

In this study, the mean age at onset and male gender preponderance were consistent with other studies $[37,38]$. The number of mild cases was lower as compared to moderate and severe cases probably because of the stringent MMSE scoring window used for mild cases in the present study. Further, our hospital is a tertiary care center, and the majority of patients referred to us were in moderate to severe conditions. Although the majority of the patients were from urban areas where the dementia care facilities are mostly concentrated, a significant proportion (38.9\%) also came from rural areas [39]. Illiteracy was a concern in our study since $76 \%$ of PwD were illiterate. As a low education level is related to low socioeconomic conditions and access to the poor health services, it has been linked with an increased risk of dementia [40].

Various epidemiological and clinical studies have reported AD as the most common cause of dementia followed by VaD worldwide [6]. The frequency of different dementia subtypes in other countries has been summarized in Table 4. Among the Indian studies, we found AD to be the most common subtype reported in all studies except one [41]. In recent studies from Mumbai [38] and Hyderabad [37], AD was reported in $45.7 \%$ and $38.3 \%$ cases; VaD was reported in $22.0 \%$ and $25.4 \%$ cases; MD was reported in $15.0 \%$ and $8.6 \%$ cases, and FTD was reported in $11.0 \%$ and $18.7 \%$ cases, respectively. In addition, PRD was reported in $<6.0 \%$ by Nair et al. [38] whereas DLB was reported in $8.6 \%$ by Alladi et al. [37]. Apart from our study, there are very few studies of MD varying in the number of patients reported from India, Nigeria, and Saudi Arabia (Table 4). High frequencies (11-27\%) of FTD among degenerative dementias have been reported in Indian studies, which is in contrast to our study which reports 7\% similar to studies from Greece and Taiwan. Further, Alladi et al. [37] in the study from Hyderabad comprising 347 dementia patients reported a high proportion of early-onset ( $<65$ years) dementia patients (49.9\%). In contrast, our study has $33.2 \%$ and $24.0 \%$ youngonset cases of $\leq 65$ and $\leq 60$ years, respectively.

Geographically, the relative proportions of dementia subtypes vary: AD predominates in Europe and North America while VaD predominates in Asian countries [42]. The proportion of $\mathrm{VaD}$ patients was found to be similar across studies from India, Oman, and Taiwan, which is higher than the findings reported from Nigeria, Greece, and Saudi Arabia (Table 4). Among 
Dementia

Cognitive Disorders

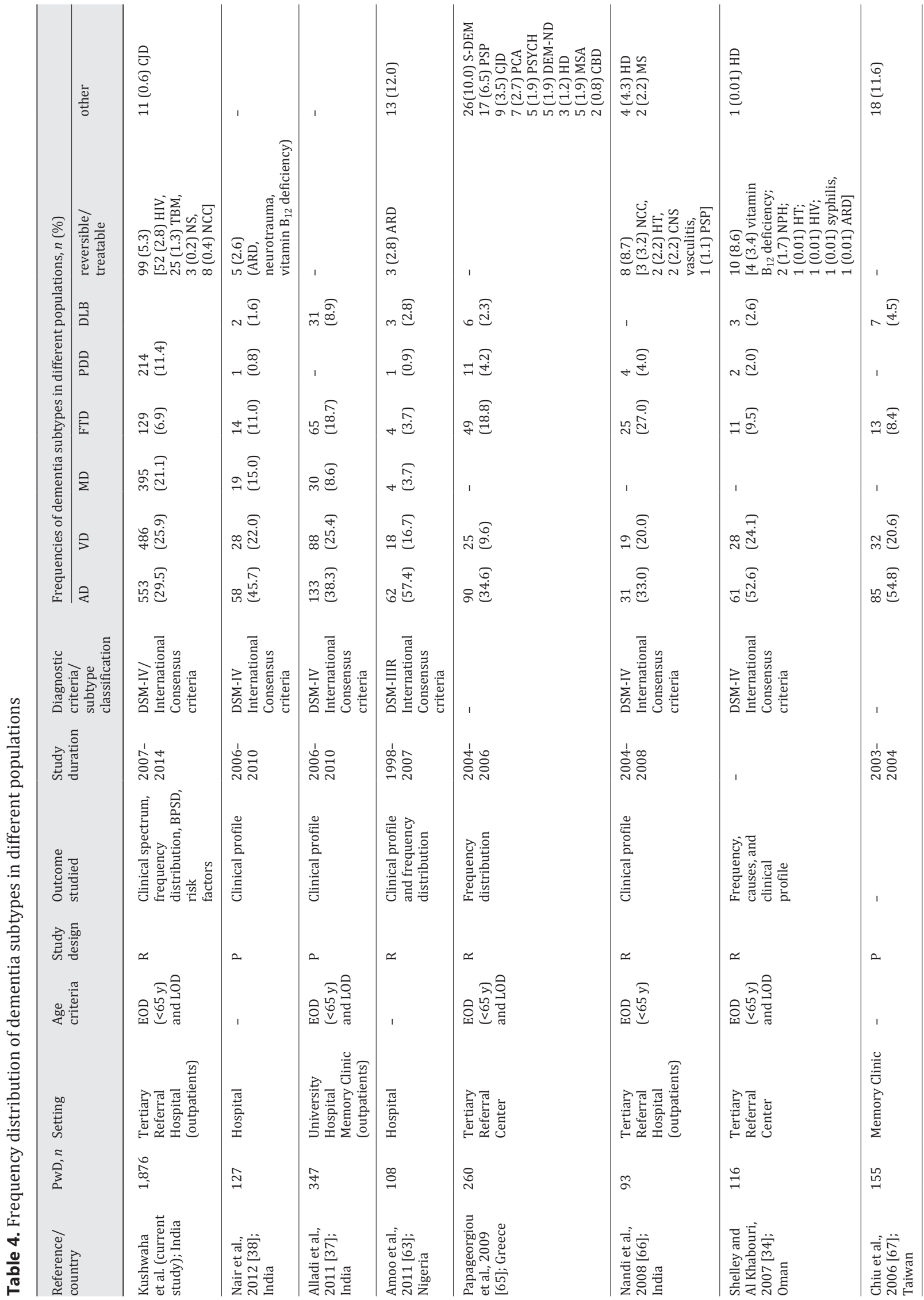


Dementia

and Geriatric
Cognitive Disorders
Dement Geriatr Cogn Disord Extra

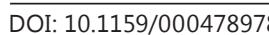

(c) 20

www.karger.com/dee

Kushwaha et al.: Dementia Subtypes in a North Indian Population

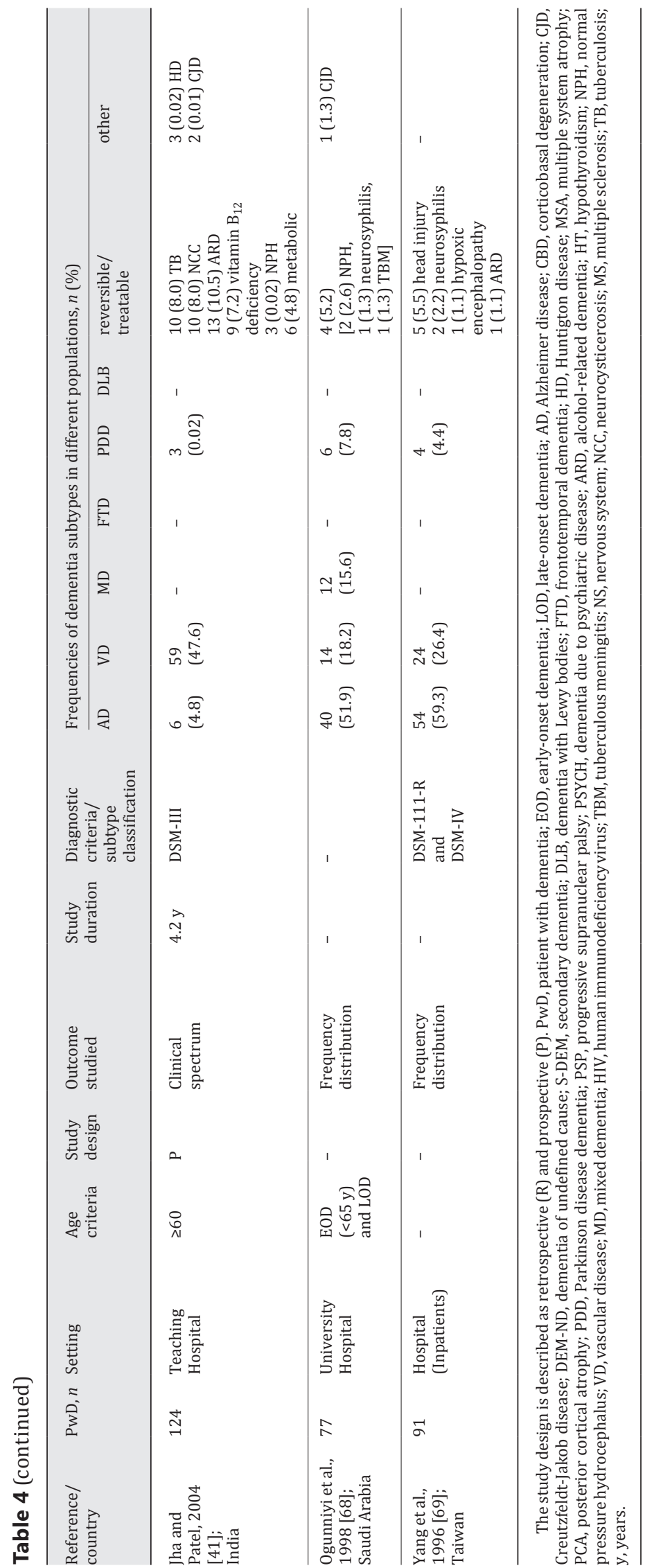




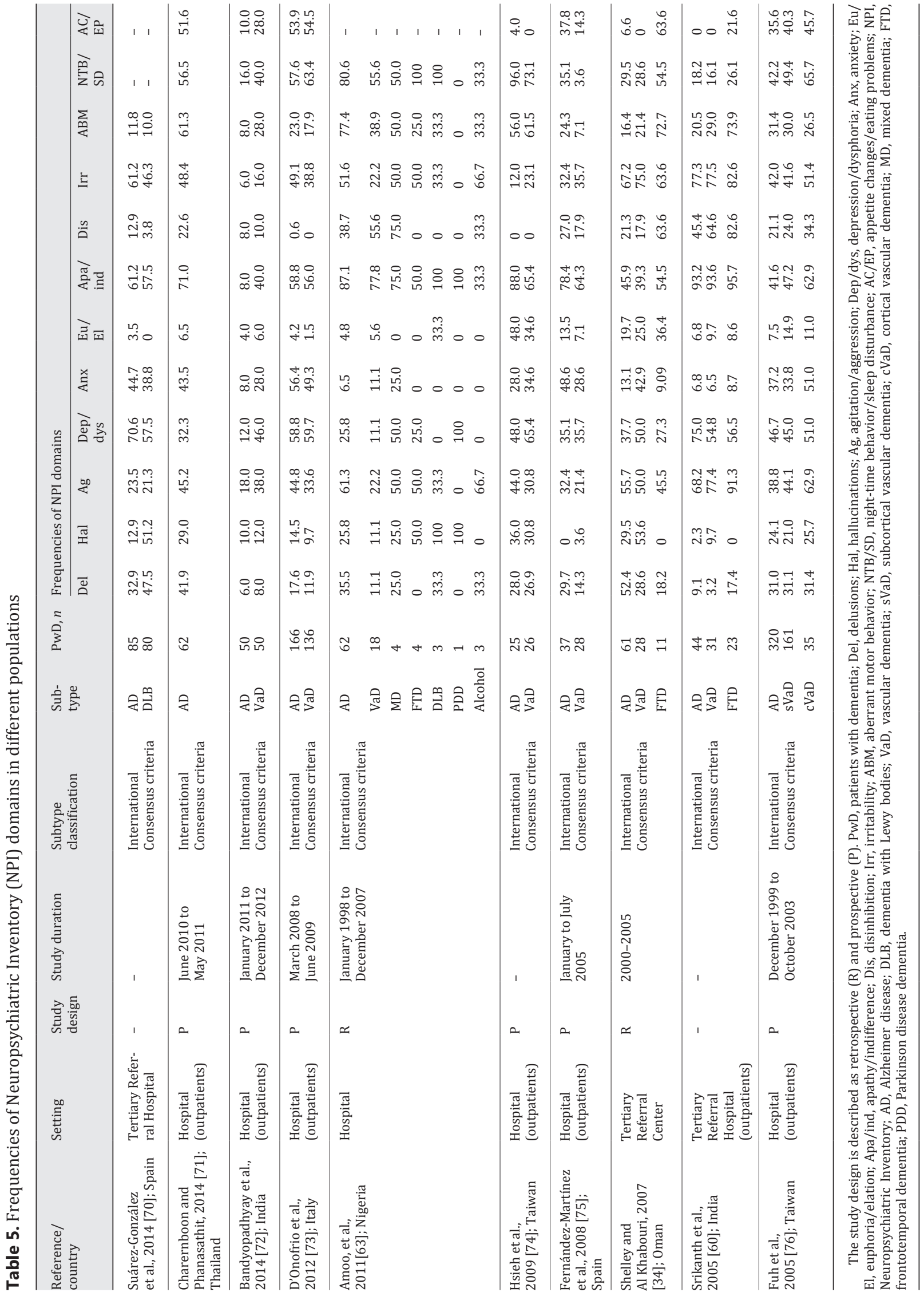


other degenerative dementias, FTD is the second most common cause of dementia in younger individuals [43]. The number of patients with $\mathrm{VaD}$ is on the rise significantly due to the increased burden of stroke in developing countries [44, 45]. In this study, VaD constitutes about $26 \%$, the second largest subtype close to the $30 \%$ of AD. Recurrent stroke predisposes to the stepwise progression in $\mathrm{VaD}$. The distribution of $\mathrm{VaD}$ subtype in our study was cortical in $42 \%$ followed by $40 \%$ mixed $\mathrm{VaD}$ (cortical + subcortical) and $17 \%$ subcortical, which is in contrast to the study from South India where subcortical dementia was the most commonly reported VaD subtype [37]. The subtype classification of $\mathrm{VaD}$ is useful for understanding the pathophysiology and for guiding the management.

The co-occurrence of $\mathrm{AD}$ and $\mathrm{VaD}$ typically referred to as MD is commonly described as a subtype of dementia with the characteristic of both $\mathrm{AD}$ and $\mathrm{VaD}$ on clinical presentation and in neuroimaging findings $[46,47]$. The true prevalence of MD is not known but it is probably the most common form of dementia [48]. Its incidence has been reported to be similar to stroke in the general population, 0.15 per 100 cases per year [49]. We found MD in 21\% of all PwD whereas in studies from Greece and Nigeria the proportion of MD reported was $15.6 \%$ and 3.7\%, respectively. There is a scarcity of studies involving MD in developing countries, which highlights the urgent need for its identification and management. Dementia in Parkinson disease has recently gained recognition [50]. PRD comprising of PDD and DLB has usually been associated with cognitive impairment. The prevalence of PDD is $0.5 \%$ in subjects of $\geq 65$ years [51]. Around $11 \%$ of the patients in our study were categorized into PRD whereas other studies have mostly reported either PDD or DLB (Table 4).

Besides degenerative dementias, potentially treatable or reversible dementias have been reported by various studies (Table 4). This heterogeneous group includes dementia due to several causes such as metabolic derangement, vitamin deficiency, endocrine dysfunction, and infective pathology. In developing countries, neuro-infections as an etiology of dementia should be investigated due to a high infection load [52]. The reported frequency of reversible dementias varies from 0 to $23 \%$ worldwide [53]. CNS infections are not found in large studies on reversible dementias from western countries [54]. While we have reported $5.3 \%$ of the cases due to various neuro-infections in our study (Fig. 2b), only few reports from other countries on infective and reversible/treatable dementias have been published (Table 4). The high prevalence of tuberculous meningitis, neurocysticercosis, and HIV dementia should always be considered while evaluating young patients with cognitive deficits in developing countries $[55,56]$. These potentially reversible and preventable causes require early diagnosis and prompt management.

Increasing age, family history, and genetic association are the most consistent risk factors associated with dementia, in particular with AD. Previous studies have established that previous stroke and vascular factors increase the risk of $A D$ and other dementias [6]. In our AD cohort $55.8 \%$ subjects had a history of hypertension, which may be a contributory risk factor for the disease. In comparison to findings from western countries, epidemiological studies have shown $\mathrm{VaD}$ as the most common form of dementia in Asian countries including India. Alladi et al. [37] showed stroke to be an important risk factor for VaD while in our study hypertension was found in $87.7 \%$ and previous stroke in $67 \%$ of patients. All patients with degenerative dementia should be screened for additional treatable co-morbid conditions such as vitamin $B_{12}$ deficiency and thyroid dysfunction as it increases the load of cognitive decline and accelerates the rate of progression contributing to co-morbidity [57]. In our study, vitamin $\mathrm{B}_{12}$ deficiency was observed in $26 \% \mathrm{PwD}$ as a co-morbid condition whereas a few other studies have reported dementia due to vitamin $\mathrm{B}_{12}$ deficiency (Table 4).

In addition to cognitive deficits, PwD usually suffer from multiple behavioral and psychotic symptoms referred to as BPSD. In recent years, more importance has been given to BPSD as they are treatable, which helps in improving the quality of life along with a reduction 
in the burden on the caregiver. Based on ethnicity and study design, the prevalence ranges from $61.0 \%$ to $92.0 \%$ [58]. Recent studies have provided the existence of the neuropsychiatric sub-syndromes which include hyperactivity, psychosis, affective symptoms, and apathy in dementia [59]. There are only few hospital-based studies from India evaluating behavioral symptoms which help in differentiating the various subtypes of dementia. Shrikanth et al. [60] made an effort in their study to differentiate between dementia subtypes on the basis of BPSD. The 10/66 group reported the prevalence of BPSD in developing countries including India. Depression in $43.8 \%$ was most predominant followed by anxiety neurosis $(14.2 \%)$ and schizophereniform/paranoid psychosis (10.9\%) [61]. Although, in our study, we have observed overlapping behavioral issues among different dementia syndromes, a significant association of certain behavioral aspects was seen with a particular dementia subtype, which is supported by previous studies (Tables 3, 5). For instance, in our AD cohort, irritability $(45.3 \%)$ was the most common BPSD followed by a tendency to wander (40.9\%), aggression (40.3\%), and suspiciousness (39.8\%) whereas perseveration, disinhibition, and apathy can be correlated with degeneration of frontal lobes in FTD [62]. BPSD in our study are consistent with the neuropsychiatric sub-syndromes described by the European Alzheimer's Disease Consortium [59]. Another study of BPSD in dementia subtypes by Amoo et al. [63] from Nigeria reported frequencies of different behavioral symptoms in dementia subtypes, and these are comparable to our study. Starkstein et al. [64] reported that apathy is a behavioral marker of more aggressive dementia, related to a faster progression of cognitive, functional, and emotional impairment. The comprehensive assessment of BPSD in dementia subtypes may help us in better understanding of disease development, progression, and management.

In conclusion, the profile of dementia subtypes varies in epidemiological and in hospitalbased studies depending on the study design, methodology, and diagnostic criteria used. The hospital-based studies are more accurate in categorizing dementia subtypes, as they involve a multidisciplinary diagnostic approach and an adequate diagnostic infrastructure in comparison to community-based studies. The burden of dementia is continuously increasing and is expected to add to the socioeconomic burden mainly in countries with limited resources. The present study showed the distribution of dementia subtypes in a tertiary care center in North India describing detailed clinical spectrum, risk factors, and behavioral abnormalities associated with dementia subtypes. We believe that comprehensive clinical profiling, assessment of risk factors and detailed BPSD evaluation are helpful in better understanding and management of dementia subtypes. Further, establishment of special clinics dedicated to cognitive disorders with a multidisciplinary team and adequate diagnostic facilities should be encouraged.

\section{Acknowledgments}

We thank Prof. Nimesh Desai, Director, Institute of Human Behaviour and Allied Sciences (IHBAS), for his vision and constant support. We are grateful to the late Dr. Ravi Nehru for his contribution to understanding cognitive disorders. We thank the anonymous reviewers for their helpful suggestions for improving the manuscript.

\section{Disclosure Statement}

The authors report no financial or other conflicts of interest relevant to the manuscript. 
Kushwaha et al.: Dementia Subtypes in a North Indian Population

\section{Author Contributions}

S.K. conceived the study, performed data retrieval and interpretation, and wrote and supervised the study. P.T. was involved in data retrieval, interpretation, and wrote the manuscript. S.K., K.B., and A.A. were involved in patient and data evaluation. V.S. contributed to neuropsychological investigations and associated data interpretation. R.A. was involved in biochemical investigations and paper writing. M.G. and R.K. contributed by providing critical input that helped in improving the manuscript. All the authors read and approved the final manuscript.

\section{References}

1 Qiu C, Kivipelto M, von Strauss E: Epidemiology of Alzheimer's disease: occurrence, determinants, and strategies toward intervention. Dialogues Clin Neurosci 2009;11:111-128.

-2 Sosa-Ortiz AL, Acosta-Castillo I, Prince MJ: Epidemiology of dementias and Alzheimer's disease. Arch Med Res 2012;43:600-608.

-3 Ferri CP, Prince M, Brayne C, Brodaty H, Fratiglioni L, Ganguli M, Hall K, Hasegawa K, Hendrie H, Huang Y, Jorm A, Mathers C, Menezes PR, Rimmer E, Scazufca M: Global prevalence of dementia: a Delphi consensus study. Lancet 2005;366:2112-2117.

-4 Rizzi L, Rosset I, Roriz-Cruz M: Global epidemiology of dementia: Alzheimer's and vascular types. Biomed Res Int 2014;2014:908915.

5 Prince MJ, Wu F, Guo Y, Gutierrez Robledo LM, O’Donnell M, Sullivan R, Yusuf S: The burden of disease in older people and implications for health policy and practice. Lancet 2015;385:549-562.

6 Kalaria RN, Maestre GE, Arizaga R, Friedland RP, Galasko D, Hall K, Luchsinger JA, Ogunniyi A, Perry EK, Potocnik F, Prince M, Stewart R, Wimo A, Zhang ZX, Antuono P: Alzheimer's disease and vascular dementia in developing countries: prevalence, management, and risk factors. Lancet Neurol 2008;7:812-826.

7 Das SK, Pal S, Ghosal MK: Dementia: Indian scenario. Neurol India 2012;60:618-624.

8 Chan KY, Wang W, Wu JJ, Liu L, Theodoratou E, Car J, Middleton L, Russ TC, Deary IJ, Campbell H, Rudan I: Epidemiology of Alzheimer's disease and other forms of dementia in China, 1990-2010: a systematic review and analysis. Lancet 2013;381:2016-2023.

-9 Leroi I, McDonald K, Pantula H, Harbishettar V: Cognitive impairment in Parkinson disease: impact on quality of life, disability, and caregiver burden. J Geriatr Psychiatry Neurol 2012;25:208-214.

10 Miller EA, Rosenheck RA, Schneider LS: Caregiver burden, health utilities, and institutional service use in Alzheimer's disease. Int J Geriatr Psychiatry 2012;27:382-393.

11 Baumgart M, Snyder HM, Carrillo MC, Fazio S, Kim H, Johns H: Summary of the evidence on modifiable risk factors for cognitive decline and dementia: a population-based perspective. Alzheimers Dement 2015;11:718726.

$\checkmark 12$ Feldman H, Kertesz A: Diagnosis, classification and natural history of degenerative dementias. Can J Neurol Sci 2001;28(suppl 1):S17-S27.

13 Kabasakalian A, Finney GR: Reversible dementias. Int Rev Neurobiol 2009;84:283-302.

14 Mendez MF, Cummings JL: Dementia: A Clinical Approach. Oxford, Butterworth-Heinemann, 2003.

15 Ironside JW, Bell JE: Infective dementias. Panminerva Med 2007;49:209-225.

16 Levy JA, Chelune GJ: Cognitive-behavioral profiles of neurodegenerative dementias: beyond Alzheimer's disease. J Geriatr Psychiatry Neurol 2007;20:227-238.

17 Cerejeira J, Lagarto L, Mukaetova-Ladinska EB: Behavioral and psychological symptoms of dementia. Front Neurol 2012;3:73.

-18 Cummings JL, Mega M, Gray K, Rosenberg-Thompson S, Carusi DA, Gornbein J: The Neuropsychiatric Inventory: comprehensive assessment of psychopathology in dementia. Neurology 1994;44:2308-2314.

-19 Folstein MF, Folstein SE, McHugh PR: "Mini-mental state." A practical method for grading the cognitive state of patients for the clinician. J Psychiatr Res 1975;12:189-198.

20 Ganguli M, Ratcliff G, Chandra V, Sharma S, Gilby J, Pandav R, Belle S, Ryan C, Baker C, Seaberg E: A Hindi version of the MMSE: the development of a cognitive screening instrument for a largely illiterate rural elderly population in India. Int J Geriatr Psychiatry 1995;10:367-377.

21 Mukundan C: NIMHANS Neuropsychological Battery: Test Descriptions, Instructions, Clinical Data and Interpretation: Proceedings of the National Workshop in Clinical Neuropsychology. Bangalore, NIMHANS Publications, 1996, vol 24, p 29.

22 Pershad D, Verma SK: Handbook of PGI Battery of Brain Dysfunction (PGI-BBD). Agra, National Psychological Corporation, 1990.

23 Diagnostic APA, and Statistical Manual of Mental Disorders, ed 4. Washington, American Psychiatric Association, 1994. 
McKhann G, Drachman D, Folstein M, Katzman R, Price D, Stadlan EM: Clinical diagnosis of Alzheimer's disease: report of the NINCDS-ADRDA Work Group under the auspices of Department of Health and Human Services Task Force on Alzheimer's Disease. Neurology 1984;34:939-944.

-25 Roman GC, Tatemichi TK, Erkinjuntti T, Cummings JL, Masdeu JC, Garcia JH, Amaducci L, Orgogozo JM, Brun A Hofman A, et al: Vascular dementia: diagnostic criteria for research studies. Report of the NINDS-AIREN International Workshop. Neurology 1993;43:250-260. Erkinjuntti T: Clinical criteria for vascular dementia: the NINDS-AIREN criteria. Dementia 1994;5:189-192. Molgaard CA: Multivariate analysis of Hachinski's Scale for discriminating senile dementia of the Alzheimer's type from multiinfarct dementia. Neuroepidemiology 1987;6:153-160.

28 Neary D, Snowden JS, Gustafson L, Passant U, Stuss D, Black S, Freedman M, Kertesz A, Robert PH, Albert M, Boone K, Miller BL, Cummings J, Benson DF: Frontotemporal lobar degeneration: a consensus on clinical diagnostic criteria. Neurology 1998;51:1546-1554.

29 Duara R, Barker W, Luis CA: Frontotemporal dementia and Alzheimer's disease: differential diagnosis. Dement Geriatr Cogn Disord 1999;10(suppl 1):37-42.

30 McKeith IG, Dickson DW, Lowe J, Emre M, O’Brien JT, Feldman H, Cummings J, Duda JE, Lippa C, Perry EK, Aarsland D, Arai H, Ballard CG, Boeve B, Burn DJ, Costa D, Del Ser T, Dubois B, Galasko D, Gauthier S, Goetz CG, Gomez-Tortosa E, Halliday G, Hansen LA, Hardy J, Iwatsubo T, Kalaria RN, Kaufer D, Kenny RA, Korczyn A, Kosaka K, Lee VM, Lees A, Litvan I, Londos E, Lopez OL, Minoshima S, Mizuno Y, Molina JA, Mukaetova-Ladinska EB, Pasquier F, Perry RH, Schulz JB, Trojanowski JQ, Yamada M: Diagnosis and management of dementia with Lewy bodies: third report of the DLB Consortium. Neurology 2005;65:1863-1872.

-31 Pagonabarraga J, Kulisevsky J, Llebaria G, Garcia-Sanchez C, Pascual-Sedano B, Gironell A: Parkinson's diseasecognitive rating scale: a new cognitive scale specific for Parkinson's disease. Mov Disord 2008;23:998-1005.

-32 Collerton D, Burn D, McKeith I, O’Brien J: Systematic review and meta-analysis show that dementia with Lewy bodies is a visual-perceptual and attentional-executive dementia. Dement Geriatr Cogn Disord 2003;16:229237.

-33 Lobo A, Launer LJ, Fratiglioni L, Andersen K, Di Carlo A, Breteler MM, Copeland JR, Dartigues JF, Jagger C, Martinez-Lage J, Soininen H, Hofman A: Prevalence of dementia and major subtypes in Europe: a collaborative study of population-based cohorts. Neurologic Diseases in the Elderly Research Group. Neurology 2000; 54:S4-S9.

-34 Shelley BP, Al Khabouri J: The spectrum of dementia: frequency, causes and clinical profile. A national referral hospital-based study in Oman. Dement Geriatr Cogn Disord 2007;24:280-287.

-35 Vas CJ, Pinto C, Panikker D, Noronha S, Deshpande N, Kulkarni L, Sachdeva S: Prevalence of dementia in an urban Indian population. Int Psychogeriatr 2001;13:439-450.

-36 Jhoo JH, Kim KW, Huh Y, Lee SB, Park JH, Lee JJ, Choi EA, Han C, Choo IH, Youn JC, Lee DY, Woo JI: Prevalence of dementia and its subtypes in an elderly urban Korean population: results from the Korean Longitudinal Study on Health and Aging (KLoSHA). Dement Geriatr Cogn Disord 2008;26:270-276.

-37 Alladi S, Mekala S, Chadalawada SK, Jala S, Mridula R, Kaul S: Subtypes of dementia: a study from a memory clinic in India. Dement Geriatr Cogn Disord 2011;32:32-38.

38 Nair G, Van Dyk K, Shah U, Purohit DP, Pinto C, Shah AB, Grossman H, Perl D, Ganwir V, Shanker S, Sano M: Characterizing cognitive deficits and dementia in an aging urban population in India. Int J Alzheimers Dis 2012;2012:673849.

-39 Prince M: Care arrangements for people with dementia in developing countries. Int J Geriatr Psychiatry 2004; 19:170-177.

40 Scazufca M, Menezes PR, Vallada HP, Crepaldi AL, Pastor-Valero M, Coutinho LM, Di Rienzo VD, Almeida OP: High prevalence of dementia among older adults from poor socioeconomic backgrounds in Sao Paulo, Brazil. Int Psychogeriatr 2008;20:394-405.

41 Jha S, Patel R: Some observations on the spectrum of dementia. Neurol India 2004;52:213-214.

-42 Suh GH, Shah A: A review of the epidemiological transition in dementia - cross-national comparisons of the indices related to Alzheimer's disease and vascular dementia. Acta Psychiatr Scand 2001;104:4-11.

43 Ratnavalli E, Brayne C, Dawson K, Hodges JR: The prevalence of frontotemporal dementia. Neurology 2002; 58:1615-1621.

44 Das SK, Banerjee TK, Biswas A, Roy T, Raut DK, Mukherjee CS, Chaudhuri A, Hazra A, Roy J: A prospective community-based study of stroke in Kolkata, India. Stroke 2007;38:906-910.

45 Bhattacharya S, Saha SP, Basu A, Das SK: A 5 years prospective study of incidence, morbidity and mortality profile of stroke in a rural community of eastern India. J Indian Med Assoc 2005;103:655-659.

-46 Langa KM, Foster NL, Larson EB: Mixed dementia: emerging concepts and therapeutic implications. JAMA 2004;292:2901-2908.

47 Korczyn AD: Mixed dementia - the most common cause of dementia. Ann NY Acad Sci 2002;977:129-134.

48 Gunstad J, Browndyke J: Understanding incidence and prevalence rates in mixed dementia; in Paul RH, Cohen R, Ott BR (eds): Vascular Dementia. Berlin, Springer, 2005, pp 245-255.

49 Brown RD, Whisnant JP, Sicks JD, O’Fallon WM, Wiebers DO: Stroke incidence, prevalence, and survival: secular trends in Rochester, Minnesota, through 1989. Stroke 1996;27:373-380.

50 Davis AA, Racette B: Parkinson disease and cognitive impairment: five new things. Neurol Clin Pract 2016; 6:452-458. 
51 Aarsland D, Zaccai J, Brayne C: A systematic review of prevalence studies of dementia in Parkinson's disease. Mov Disord 2005;20:1255-1263.

52 Ghosh A: Endocrine, metabolic, nutritional, and toxic disorders leading to dementia. Ann Indian Acad Neurol 2010;13:S63-68.

53 Clarfield AM: The decreasing prevalence of reversible dementias: an updated meta-analysis. Arch Intern Med 2003;163:2219-2229.

54 Walstra GJ, Teunisse S, van Gool WA, van Crevel H: Reversible dementia in elderly patients referred to a memory clinic. J Neurol 1997;244:17-22.

55 Almeida OP, Lautenschlager NT: Dementia associated with infectious diseases. Int Psychogeriatr 2005; 17(suppl 1):S65-S77.

56 Srikanth S, Nagaraja AV: A prospective study of reversible dementias: frequency, causes, clinical profile and results of treatment. Neurol India 2005;53:291-294; discussion 294-296.

-57 Issac TG, Soundarya S, Christopher R, Chandra SR:Vitamin B12 deficiency: an importantreversible co-morbidity in neuropsychiatric manifestations. Indian J Psychol Med 2015;37:26-29.

58 Fernandez M, Gobartt AL, Balana M: Behavioural symptoms in patients with Alzheimer's disease and their association with cognitive impairment. BMC Neurol 2010;10:87.

59 Aalten P, Verhey FR, Boziki M, Brugnolo A, Bullock R, Byrne EJ, Camus V, Caputo M, Collins D, De Deyn PP, Elina K, Frisoni G, Holmes C, Hurt C, Marriott A, Mecocci P, Nobili F, Ousset PJ, Reynish E, Salmon E, Tsolaki M, Vellas B, Robert PH: Consistency of neuropsychiatric syndromes across dementias: results from the European Alzheimer Disease Consortium. Part II. Dement Geriatr Cogn Disord 2008;25:1-8.

-60 Srikanth S, Nagaraja AV, Ratnavalli E: Neuropsychiatric symptoms in dementia-frequency, relationship to dementia severity and comparison in Alzheimer's disease, vascular dementia and frontotemporal dementia. J Neurol Sci 2005;236:43-48.

61 Ferri CP, Ames D, Prince M: Behavioral and psychological symptoms of dementia in developing countries. Int Psychogeriatr 2004;16:441-459.

62 Ghosh A, Dutt A: Utilisation behaviour in frontotemporal dementia. J Neurol Neurosurg Psychiatry 2010; 81:154-156.

63 Amoo G, Akinyemi RO, Onofa LU, Akinyemi JO, Baiyewu O, Ogunlesi AO, Ogunniyi A: Profile of clinically-diagnosed dementias in a neuropsychiatric practice in Abeokuta, south-western Nigeria. Afr J Psychiatry (Johannesbg) 2011;14:377-382.

-64 Starkstein SE, Jorge R, Mizrahi R, Robinson RG: A prospective longitudinal study of apathy in Alzheimer's disease. J Neurol Neurosurg Psychiatry 2006;77:8-11.

65 Papageorgiou SG, Kontaxis T, Bonakis A, Kalfakis N, Vassilopoulos D: Frequency and causes of early-onset dementia in a tertiary referral center in Athens. Alzheimer Dis Assoc Disord 2009;23:347-351.

66 Nandi SP, Biswas A, Pal S, Basu S, Senapati AK, Das SK: Clinical profile of young-onset dementia: a study from Eastern India. Neurol Asia 2008;13:103-108.

67 Chiu MJ, Chen TF, Yip PK, Hua MS, Tang LY: Behavioral and psychologic symptoms in different types of dementia. J Formos Med Assoc 2006;105:556-562.

-68 Ogunniyi A, Daif AK, Al-Rajeh S, AbdulJabbar M, Al-Tahan AR, Al-Bunyan M, Shamina AR: Dementia in Saudi Arabia: experience from a university hospital. Acta Neurol Scand 1998;98:116-120.

69 Yang CH, Hwang JP, Tsai SJ, Liu KM: Types and phenomenologic subtypes of dementia in Taiwan: a psychiatric inpatient study. Int J Geriatr Psychiatry 1996;11:705-709.

-70 Suárez-González A, Serrano-Pozo A, Arroyo-Anllo EM, Franco-Macias E, Polo J, Garcia-Solis D, Gil-Neciga E: Utility of neuropsychiatric tools in the differential diagnosis of dementia with Lewy bodies and Alzheimer's disease: quantitative and qualitative findings. Int Psychogeriatr 2014;26:453-461.

-71 Charernboon T, Phanasathit M: Prevalence of neuropsychiatric symptoms in Alzheimer's disease: a crosssectional descriptive study in Thailand. J Med Assoc Thai 2014;97:560-565.

72 Bandyopadhyay TK, Biswas A, Roy A, Guin DS, Gangopadhyay G, Sarkhel S, Ghoshal MK, Senapati AK: Neuropsychiatric profiles in patients with Alzheimer's disease and vascular dementia. Ann Indian Acad Neurol 2014; 17:325-330.

-73 D’Onofrio G, Sancarlo D, Panza F, Copetti M, Cascavilla L, Paris F, Seripa D, Matera MG, Solfrizzi V, Pellegrini F, Pilotto A: Neuropsychiatric symptoms and functional status in Alzheimer's disease and vascular dementia patients. Curr Alzheimer Res 2012;9:759-771.

74 Hsieh CJ, Chang CC, Lin CC: Neuropsychiatric profiles of patients with Alzheimer's disease and vascular dementia in Taiwan. Int J Geriatr Psychiatry 2009;24:570-577.

75 Fernández-Martínez M, Castro J, Molano A, Zarranz JJ, Rodrigo RM, Ortega R: Prevalence of neuropsychiatric symptoms in Alzheimer's disease and vascular dementia. Curr Alzheimer Res 2008;5:61-69.

-76 Fuh JL, Wang SJ, Cummings JL: Neuropsychiatric profiles in patients with Alzheimer's disease and vascular dementia. J Neurol Neurosurg Psychiatry 2005;76:1337-1341. 